\title{
The assessment of vitamin A status
}

\section{By G. A. J. Pirt, Department of Biochemistry, University of Liverpool, P.O. Box 147 , Liverpool L69 $3^{B X}$}

Nature has provided us with an excellent means of assessing the vitamin A status of man and animals: from the size of the vitamin A stores in the liver.

Vitamin $A$ comes in the diet either as retinol, usually esterified, or as a carotenoid precursor that can be split to give retinol. Whatever its origin, retinol is esterified in the intestinal mucosa with long-chain fatty acids and taken to the liver.

The liver stores retinyl esters as the body's reserve of vitamin A. They can be hydrolysed to retinol, which can be attached in the liver to a specific carrier protein, retinol-binding protein (RBP), to be put into the plasma as the vehicle for transporting retinol to tissues that need it (Smith \& Goodman, 1979; Goodman, 1980).

If an animal receives more vitamin $A$ than it requires, the excess is stored in the liver as retinyl esters, which therefore increase. Should the dietary supply of vitamin A be inadequate, these reserves can be drawn upon to supply retinol to other tissues and the liver stores of retinyl esters will run down. Therefore to know the vitamin A status of a subject, one merely has to determine the vitamin A content of the liver.

This can readily be done on post-mortem samples. Certain precautions are necessary, for example, vitamin A stores tend to be distributed asymmetrically in the liver (McLaren et al. 1979; Olson et al. 1979), but analytical methods for vitamin $A$ are sensitive and adequately accurate (Underwood, 1974). The most commonly used procedures are based on the blue colour reaction given with Lewis acids such as antimony trichloride (Ames et al. 1954) or its more modern replacements, trifluoroacetic acid (Neeld \& Pearson, 1963) or trichloroacetic acid (Bayfield \& Cole, 1980). By such means it has been possible to establish the vitamin A status of the human population of numerous countries and of many animals in different conditions.

For the determination of vitamin $A$ one needs a sample of liver. The method is therefore excellent for assessing the vitamin A status after death, but not very useful for living animals, as it is usually unethical or impracticable to take liver biopsy samples for this purpose. Blood can readily be obtained, to determine the vitamin A content of plasma or serum, but unfortunately this is less useful than the liver vitamin A concentration as a measure of vitamin A status.

In the postabsorptive state, when no retinyl esters are passing from the intestine to the liver, the vitamin $A$ in the blood consists almost wholly of retinol, combined with RBP. Plasma vitamin A can readily be determined by the procedures used for liver analysis and by even more sensitive methods such as high performance liquid $0029-665 \mathrm{I} / 81 / 4023-5004$ S01.00 (C) 1981 The Nutrition Society 
chromatography (e.g. De Ruyter \& De Leenheer, 1978) and fluorimetric assay (Glover, 1980).

Retinol fluoresces with an emission maximum near $470 \mathrm{~nm}$. This property has frequently been used to determine vitamin $A$, not always very successfully, because of quenching and interference from other fluorescing material (see Thompson et al. 1971). Combination with RBP, however, enhances the fluorescence of retinol by an order of magnitude (Goodman \& Leslie, 1972; Futterman \& Heller, 1972; Glover, I980). Fluorescence determinations of plasma retinol as the RBP complex are therefore very sensitive and have the advantage of being little affected by any retinyl esters in transit from the intestine to the liver; that is, they measure the retinol put out by the liver on RBP for the supply of tissues (Glover, 1980).

Although determination of plasma retinol as the retinol-RBP complex would appear to be a promising method for assessing the vitamin A status of living animals, there are limitations on its value. The major one is that there is some mechanism, not yet understood, that keeps the plasma retinol concentration reasonably constant to supply vitamin A to tissues. Although there is some relationship between the plasma concentration and liver content of the vitamin (Wright \& Hall, 1979), provided the liver reserves of retinyl esters are above a very low level the size of the reserves has relatively little effect on the plasma retinol concentration (Peterson et al. 1973; Underwood, 1974; Loerch et al. 1979; Keilson et al. 1979; Underwood et al. 1979). Only if the liver reserves are effectively exhausted does the plasma concentration fall substantially. A low plasma retinol concentration can therefore be a valuable indication that the liver reserves have disappeared, but plasma retinol concentrations do not distinguish well between subjects with low and high liver reserves.

Furthermore, the level at which this homoeostatic mechanism is set is influenced by factors, other than the retinol status of the animal, that influence the output of RBP or the retinol-RBP complex by the liver.

If dietary protein is inadequate, insufficient RBP is biosynthesized in the liver, and the plasma retinol concentration will consequently fall, regardless of the retinol status of the animal (Arroyave et al. 1961; Friend et al. 1961; Smith, Goodman, Zaklama et al. 1973; Smith, Goodman, Arroyave et al. r973; Muhilal \& Glover, I974; Glover \& Muhilal, I976).

Various diseases can affect the output of the retinol-RBP complex by the liver or its metabolism by the kidney, thus lowering or raising the plasma retinol concentration (Smith \& Goodman, 1971; Kindler, 1972; Underwood, 1974).

The secretion of the retinol-RBP complex by the liver is under endocrinological control to some extent, so the plasma retinol concentration is influenced by the pattern of reproduction in an animal (Glover et al. 1976; Glover et al. 1980). Oestrogens and oral contraceptives can increase plasma retinol-RBP concentrations (Anon. 1979; Ram \& Bamji, 1979).

The retinol requirements of tissues also influence, by some unknown mechanism, the plasma retinol-RBP concentration, so poor growth depresses and accelerated growth increases the plasma retinol concentration (Carney et al. 1976; Underwood 
et al. 1979). Giving retinoids other than retinol, thereby improving the vitamin $A$ status, can, apparently paradoxically, depress the plasma retinol concentration as a consequence of diminishing the demand of tissues for retinol itself (Underwood et al. 1979; Keilson et al. 1979; Loerch et al. 1979). So plasma retinol concentrations can go up and down for reasons unconnected with the vitamin $A$ status of the body.

To try to distinguish whether a low plasma retinol concentration is due to an inadequate supply of vitamin A or some other cause, Loerch et al. (I979) have put forward the concept of the 'relative dose response' of plasma retinol, based on the increase in the plasma retinol concentration brought about by a dose of vitamin $A$. If a low plasma retinol concentration is due to lack of retinyl ester reserves in the liver, the relative dose response is high; if the low plasma concentration is due to other factors, giving extra retinol will have little effect. The method has been worked out on rats; it will be interesting to see how valuable it will be in field conditions, especially in investigations on humans. Even without this refinement, however, a low plasma retinol concentration has been a widely used indicator of vitamin A deficiency in man, e.g. values below $20 \mu \mathrm{g} / \mathrm{dl}$ raise doubts about vitamin A status; a concentration below $10 \mu \mathrm{g} / \mathrm{dl}$ is a strong indication of vitamin $A$ deficiency (see Underwood, 1974).

With some vitamins it is possible to determine the status of individuals by measuring some dependent physiological function, e.g. riboflavin-containing enzymes (Thurnham, 1981).

Vitamin A operates in vision as retinaldehyde, which forms the chromophoric group of visual pigments; if there is insufficient vitamin $A$, inadequate amounts of visual pigment are formed. In man, rhodopsin, concerned with low-intensity vision, is first affected. The consequent increase in visual threshold has often been used as a measure of vitamin A status in man (Rodriguez \& Irwin, 1972; Peterson et al. 1974; Carney \& Russell, 1980), and vitamin A deficiency has been detected successfully (Russell et al. 1973; Carney \& Russell, 1980). It could be a particularly valuable measurement when considered with the plasma retinol concentration. A lowish plasma retinol concentration might be fortuitous; poor dark adaptation would confirm vitamin A deficiency. Dark adaptation can be faulty for reasons other than vitamin A deficiency (Morrison et al. 1978; see Carney \& Russell, 1980) so a diagnosis of vitamin A deficiency ought to be supported by a low plasma retinol concentration. Sometimes, however, the rise in visual threshold is observed only after the plasma retinol has fallen to a very low concentration and so in some individuals it will be a less sensitive indication of vitamin A deficiency (Sauberlich et al. 1974). It would not be practicable to use the dark adaptation test widely because of the cost of the apparatus and, as the test requires a co-operative and attentive subject, it is unsuitable for young children, who are particularly at risk from vitamin A deficiency (Carney \& Russell, 1980).

More important than its function in vision is the systemic role of vitamin A, concerned with the maintenance of life, growth and general health. It is not known in molecular terms how the vitamin discharges this function, but failure results in a 
wide range of deficiency signs that can differ between species (Moore, 1967). For example, in chickens one sees ataxia (Howell \& Thompson, 1967); in adult man, a skin lesion, follicular hyperkeratosis (Hume \& Krebs, 1949; Sauberlich et al. 1974); in children, xerophthalmia (Oomen, 1976).

Observed deficiency signs can be used to diagnose frank vitamin A deficiency, but otherwise they are in general inferior to the plasma retinol concentration as a means of assessing vitamin $A$ status. One might reasonably expect this. The characteristic deficiency signs result from an inadequate amount of the vitamin in the functional tissue. As vitamin A has to arrive there in the form of the retinol$\mathrm{RBP}$ complex, any inadequacy is likely to be detectable earlier, in the transport system.

As by far the best indication of vitamin A status is its concentration in the liver, an obvious need is to devise some means of measuring the liver vitamin $A$ in life. Various ideas have been tried, but with only limited success.

One approach has been to use isotopic dilution. Isotopically labelled vitamin $A$ is injected or given; time is allowed for it to equilibrate with the pre-existing body pool of vitamin $A$; from the ratio of unlabelled retinol:labelled retinol in the plasma the amount of unlabelled vitamin in the body can be calculated. (Assumptions have to be made, however, about how much of the isotopically labelled vitamin given actually reaches the liver.)

Rietz et al. (1973) and Rietz et al. (1974) used tritiated retinyl acetate on rats; Sauberlich et al. (1974) used ${ }^{14} \mathrm{C}$-labelled retinol or retinyl acetate on human volunteers. Rietz et al. (1973) and Rietz et al. (1974) were able to check their calculated values with the determined vitamin A content of the livers (effectively equivalent to the body pool of the vitamin); agreement was excellent.

Radioactive vitamin A cannot be given routinely to humans or animals; an isotopic dilution method suitable for widespread use would have to be based on stable isotopes. Hughes et al. (I 976) used deuterated vitamin A in rats, and their calculated values agreed reasonably well with those determined by liver analyses-not as well as with the tritiated material used by Rietz et al. (1974), but good enough for practical purposes. The big problem with stable isotope dilution methods is the determination of unlabelled retinol:labelled retinol in plasma. Hughes et al. (I976) used gas chromatography-mass spectrometry, but this is a procedure likely to be too elaborate for routine investigations or surveys.

Another indirect approach to an estimate of the body store of retinol has been to measure the excretion of metabolites of vitamin A (Varma \& Beaton, I972; Rietz et al. 1974). Vitamin A in the body (mainly retinyl esters in the liver) is destroyed at a fairly steady rate, roughly proportional to the size of the liver retinyl ester stores (Sundaresan, 1977). Rietz et al. (1974) were able to establish the chemical nature of some of these characteristic metabolites in urine and faeces but found a very poor correlation between the excretion of these compounds and the size of the liver stores.

At the moment the only practicable way of determining the liver reserves of vitamin A is by analysis of a liver sample, which restricts the method to post- 
mortem material. For living animals the plasma vitamin A concentration has perforce to be used as a means of assessing vitamin A status, despite its known limitations.

Those working in the field may be somewhat disappointed that it has not been possible to take greater advantage of the fact that in the liver stores of retinyl esters we have an excellent index of vitamin A status. But in practice does it matter much if we are restricted to post-mortem samples?

Post-mortem analyses of liver will indicate whether human populations or groups of animals contain significant numbers of individuals at risk from vitamin $A$ deficiency (see, for example, Olson, I979). If they do, the problem can be dealt with by giving all in the group vitamin $A$ supplements; vitamin $A$ is readily available and relatively cheap. This approach is quicker and probably less costly than trying to work out which individuals are at risk.

Whatever their shortcomings on paper, the methods for assessing vitamin A status are reasonably adequate in practice. They have revealed clearly the wide prevalence of vitamin A deficiency in man, and their efficacy is much superior to our still stumbling efforts to overcome the economic, social and political obstacles that prevent the elimination of vitamin A deficiency from the world.

\section{REFERENCES}

Ames, S. R., Risley, H. A. \& Harris, P. L. (1954). Anal. Chem. 26, 1378.

Anon. (1979). Nutr. Rev. 37, 346.

Arroyave, G., Wilson, D., Méndez, J., Béhar, M. \& Scrimshaw, N. S. (rg6r). Am. F. clin. Nutr. 9, 180.

Bayfield, R. F. \& Cole, E. R. (1980). Meth. Enzymol. 67, 189.

Carney, E. A. \& Russell, R. M. (1980). 7. Nutr. 110, $55^{2}$.

Carney, S. M., Underwood, B. A. \& Loerch, J. A. (1976). F. Nutr. 106, 1773.

De Ruyter, M. G. M. \& De Leenheer, A. P. (1978). Clin. Chem. 24, 1920.

Friend, C. J., Heard, C. R. C., Platt, B. S., Stewart, R. J. C. \& Turner, M. R. (I96r). Br. J. Nutr. $15,23 \mathrm{I}$.

Futterman, S. \& Heller, J. (1972). F. biol. Chem. 247, 5168.

Glover, J. (1980). Meth. Enzymol. 67, 282.

Glover, J., Heaf, D. J. \& Large, S. (1980). Br. F. Nutr. 43, 357.

Glover, J., Jay, C., Kershaw, R. C. \& Reilly, P. E. B. (1976). Br. F. Nutr. 36, 137.

Glover, J. \& Muhilal, H. (1976). Int. F. Vitam. Nutr. Res. 46, 239.

Goodman, D. S. (1980). Fedn Proc. Fedn Am. Socs exp. Biol. 39, 2716.

Goodman, D. S. \& Leslie, R. B. (I 972). Biochim. biophys. Acta. 260, 670.

Howell, J. McC. \& Thompson, J. N. (1967). Br. F. Nutr. 21, 74r.

Hughes, D. R., Rietz, P., Vetter, W. \& Pitt, G. A. J. (1976). Int. F. Vitam. Nutr. Res. 46, 23 I.

Hume, E. M. \& Krebs, H. A. (1949). Spec. Rep. Ser. med. Res. Coun. 264.

Keilson, B., Underwood, B. A. \& Loerch, J. D. (1979). F. Nutr. I09, 787.

Kindler, U. (1972). Dr. med. Wschr. 97, $182 \mathrm{I}$.

Loerch, J. D., Underwood, B. A. \& Lewis, K. C. (1979). F. Nutr. rog, 778.

McLaren, D. S., Mawlayi, Z. \& Downing, A. (1979). Proc. Nutr. Soc. 38, 49 A.

Moore, T. (I967). In The Vitamins, and ed., vol. I, p. 245 [W. H. Sebrell and R. S. Harris, editors]. New York: Academic Préss.

Morrison, S. A., Russell, R. M., Carney, E. A. \& Oaks, E. V. (1978). Am. F. clin. Nutr. 31, 276.

Muhilal, H. \& Glover, J. (1974). Br. F. Nutr. 32, 549.

Neeld, J. B. \& Pearson, W. N. (1963). F. Nutr. 79, 454 .

Olson, J. A. (1979). Archos. lat.-am. Nutr. 29, 52 I.

Olson, J. A., Gunning, D. \& Tilton, R. (1979). Am. f. clin. Nutr. 32, 2500. 
Oomen, H. A. P. C. (1976). In Nutrition in Preventive Medicine, p. 94 [G. H. Beaton and J. M. Bengoa, editors]. Geneva: World Health Organization.

Peterson, P. A., Nilsson, S. F., Östberg, L., Rask, L. \& Vahlquist, A. (I974). Vitam. Horm. 32, I $8 \mathrm{I}$.

Peterson, P. A., Rask, L., Östberg, L., Andersson, L., Kamwendo, F. \& Pertoft, H. (1973). F. biol. Chem. 248, 4009 .

Ram, M. M. \& Bamji, M. S. (1979). Am. F. Obstet. Gynaec. 135, 470.

Rietz, P., Vuilleumier, J. P., Weber, F. \& Wiss, O. (1973). Experientia 29, 168.

Rietz, P., Wiss, O. \& Weber, F. (1974). Vitam. Horm. 32, 237.

Rodriguez, M. S. \& Irwin, M. I. (1972). F. Nutr. 102, 909.

Russell, R. M., Smith, V. C., Multack, R., Krill, A. E. \& Rosenberg, I. H. (1973). Lancet ii, I 6 I.

Sauberlich, H. E., Hodges, R. E., Wallace, D. L., Kolder, H., Canham, J. E., Hood, J., Raica, N. \& Lowry, L. K. (I974). Vitam. Horm. 32, 25 I.

Smith, F. R. \& Goodman, D. S. (I97I). F. clin. Invest. 50, 2426.

Smith, F. R., Goodman, D. S., Arroyave, G. \& Viteri, F. (1973). Am. F. clin. Nutr. 26, 982.

Smith, F. R., Goodman, D. S., Zaklama, M. S., Gabr, M. K., El Maraghy, S. \& Patwardhan, V. K. (1973). Am. F. clin. Nutr. 26, 973 .

Smith, J. E. \& Goodman, D. S. (1979). Fedn Proc. Fedn Am. Socs exp. Biol. 38, 2504.

Sundaresan, P. R. (1977). f. Nutr. 107, 70.

Thompson, J. N., Erdody, P., Brien, R. \& Murray, T. K. (I97I). Biochem. Med. 5, 67.

Thurnham, D. I. (198r). Proc. Nutr. Soc. 40, 155.

Underwood, B. A. (1974). Wld Rev. Nutr. Diet. 19, 123.

Underwood, B. A., Loerch, J. D. \& Lewis, K. C. (1979). F. Nutr. ro9, 796.

Varma, R. N. \& Beaton, G. H. (1972). Can. F. Physiol. Pharmac. 50, 1026.

Wright, K. E. \& Hall, R. C. (1979). J. Nutr. 109, 1063. 